\title{
Highly Strained Heterocycles Constructed from Boron-Boron Multiple Bonds and Heavy Chalcogens
}

\author{
Holger Braunschweig, ${ }^{*}[\mathrm{a}]$ Philipp Constantinidis, ${ }^{[b]}$ Theresa Dellermann, ${ }^{[a]}$ William C. Ewing, ${ }^{[a]}$ Ingo \\ Fischer, ${ }^{[b]}$ Merlin Hess, ${ }^{[a]}$ Fergus R. Knight, ${ }^{[d]}$ Anna Rempel, ${ }^{[a]}$ Christoph Schneider, ${ }^{[a]}$ Stefan Ullrich, ${ }^{[a]}$ \\ Alfredo Vargas, ${ }^{[c]} \mathrm{J}$. Derek Woollins ${ }^{[\mathrm{d}]}$
}

\begin{abstract}
The reactions of a diborene with elemental selenium or tellurium are shown to afford a diboraselenirane or diboratellurirane, respectively. These reactions are reminiscent of the sequestration of sub-valent oxygen and nitrogen in the formation of oxiranes and aziridines; however, such reactivity is not known between alkenes and the heavy chalcogens. While carbon is too electronegative to affect the reduction of elements of lower relative electronegativity, the highly reducing nature of the $\mathrm{B}=\mathrm{B}$ double bond enables reactions with $\mathrm{Se}^{0}$ and $\mathrm{Te}^{0}$. The capacity of multiple bonds between boron to donate electron density is highlighted in reactions where diborynes behave as nucleophiles, attacking one of the two Te atoms of diaryltellurides, forming salts consisting of diboratellurenium cations and aryltelluride anions.
\end{abstract}

The energy stored in small, highly strained cyclic molecules has made them an integral part of modern synthetic chemistry. Since this "strain energy" increases with decreasing ring size, it is greatest for three-membered rings, and when these rings are heterocyclic the charge-asymmetry induced in the molecule provides sites ready for reaction. Accordingly, an enormous amount of research has gone into both the synthetic methods to, and reactions of, members of this class of compounds, most prominently oxiranes $\left(\mathrm{C}_{2} \mathrm{O}\right.$ rings $)$ and aziridines $\left(\mathrm{C}_{2} \mathrm{~N}\right.$ rings). The most common route to these materials is the oxidation of olefins using, in the case of oxirane formation, subvalent oxygen species such as $\mathrm{O}_{2}$, peroxides, peroxyacids, and ozone, or with reagents that impart a degree of electron deficiency to an oxygen atom, such as chlorite or iodosylbenzene ${ }^{[1]}$ Aziridination of olefins is most frequently accomplished through the in situ generation of nitrenes from azides or other electron deficient nitrogen sources such as iodinanes, hydroxylamines, and hydrazines. ${ }^{[1 a, 2]}$ These alkene-oxidations are made possible by

[a] Prof. Dr. H. Braunschweig, ${ }^{*}$ Ms. T. Dellermann, Dr. W. C. Ewing Ms. A. Rempel, Mr. C. Schneider, Mr. S. Ullrich, Institut für Anorganische Chemie Julius-Maximilians-Universität Würzburg Am Hubland, 97074 Würzburg, Germany E-mail: h.braunschweig@uni-wuerzburg.de

[b] Prof. Dr. I. Fischer, ${ }^{*}$ Mr. P. Constantinidis Institut für Physikalische und Theoretische Chemie Julius-Maximilians-Universität Würzburg Am Hubland, 97074 Würzburg, Germany

[c] Dr. A. Vargas

Department of Chemistry

School of Life Sciences,

University of Sussex,

Brighton BN1 9QJ, Sussex (UK)

[d] Prof. J. D. Woollins, Dr. F. R. Knight

School of Chemistry, University of St Andrews

Fife, KY16 9ST (UK)

Supporting information for this article is given via a link at the end of the document. the relatively high electronegativity of oxygen and nitrogen, $\left(X_{\text {Pauling }}=3.44\right.$ and 3.04 , respectively), relative to carbon (XPauling $=2.55)$.

Thiiranes $\left(\mathrm{C}_{2} \mathrm{~S}\right.$ rings $)$ are comparatively less common, and though examples of the direct addition of elemental sulfur to alkenyl double bonds are not unknown, ${ }^{[3]}$ their syntheses are more likely than their first row neighbors to involve non-redox routes. ${ }^{[4]}$ The similar electronegativities of carbon and sulfur (XPauling $=2.58$ ) decreases the thermodynamic driving force for alkene oxidation, further exemplified by the noted willingness of thiiranes to thermally extrude atomic sulfur ${ }^{[5]}$ and by their utility as sulfur atom transfer reagents. ${ }^{[6]}$ Three-membered heterocycles featuring heavier chalcogens ( $\mathrm{Se}$ and $\mathrm{Te}$ ) are even less prevalent. Though seleniranes have been proposed as reactive intermediates in a handful of transformations, ${ }^{[7]}$ the isolated examples of these compounds are few and none have been crystallographically verified. ${ }^{[8]}$ To date, there are no known examples of telluriranes. The heavy chalcogens have roughly equal ( $\left.X_{S e}=2.55\right)$ or smaller $\left(X_{T e}=2.10\right)$ electronegativities than carbon. As such, there is little or no driving force for the transfer of electron density from the alkene to form $\mathrm{C}_{2} \mathrm{Se}$ or $\mathrm{C}_{2} \mathrm{Te}$ rings, and hypothetical seleniranes or telluriranes would logically be thermodynamically unstable toward the alkene reclaiming its electrons by expelling the electropositive chalcogen.

For some time our group has been interested in the syntheses and utilities of diborenes. ${ }^{[9]}$ In comparison to alkenes, the $\mathrm{B}=\mathrm{B}$ bonds of diborenes have been found to be exceptionally reducing, ${ }^{[10]}$ which is not surprising when considering both the formal +1 charge on boron and the lower electronegativity of boron (XPauling $=2.04$ ) than carbon. Indeed, while direct oxidation of alkenes to thiiranes with elemental sulfur is rare, the reaction of diborenes with $\mathrm{S}_{8}$ results in the transfer of all four reducing equivalents of the double bond to three sulfur atoms in the formation of a five-membered trithiadiborolane. ${ }^{[11]}$ Might these highly reductive double bonds be capable of reaction with elemental $\mathrm{Se}$ and $\mathrm{Te}$ to form stable diboraseleniranes and diboratelluriranes?

When a thienyl-substituted, $\mathrm{N}$-heterocyclic carbene (NHC) stabilized diborene (1, IMe $\left[5-\left(\mathrm{Me}_{3} \mathrm{Si}\right) \mathrm{C}_{4} \mathrm{H}_{2} \mathrm{~S}\right]_{2} \mathrm{~B}_{2}, \quad \mathrm{IMe}=1,3-$ dimethylimidazol-2-ylidene) was reacted with excess elemental selenium in benzene, a color change from the deep purple of 1 to yellow was observed, along with the emergence of a new signal at $-14 \mathrm{ppm}$ in its ${ }^{11} \mathrm{~B}$ NMR spectrum. An equivalent reaction with elemental tellurium evidenced a similar change, with the emergence of a signal at $-13 \mathrm{ppm}$ in the ${ }^{11} \mathrm{~B}$ NMR spectrum concomitant with the change of color from purple to yellow. After filtration to remove the excess chalcogen, recrystallization from acetonitrile yielded pure 2 and $\mathbf{3}$, the desired diboraselenirane and diboratelluriane, respectively. Both were structurally characterized by single-crystal $\mathrm{X}$-ray crystallography (Figure 1). ${ }^{[12]}$ Though neither ${ }^{77} \mathrm{Se}$ nor ${ }^{125} \mathrm{Te}$ nuclei could be detected by NMR spectroscopy with $\mathbf{2}$ and $\mathbf{3}$, likely a result of extensive quadrupolar broadening induced by proximity to multiple boron nuclei, the ${ }^{1} \mathrm{H}$ NMR spectra of the 
compounds are consistent with the solid-state structures, as is the upfield shift of the ${ }^{11} \mathrm{~B}$ NMR resonances from the resonance at $22 \mathrm{ppm}$ found for $\mathbf{1}$, indicative of an increase in coordination number at boron.

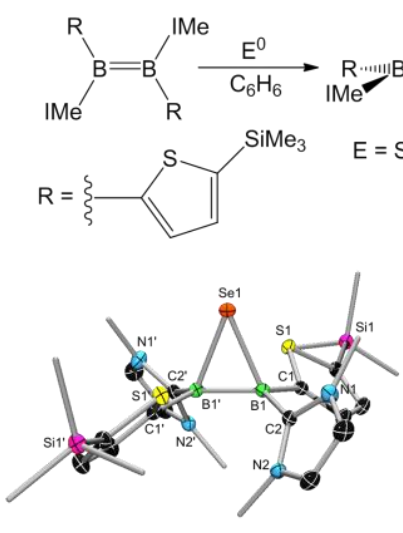

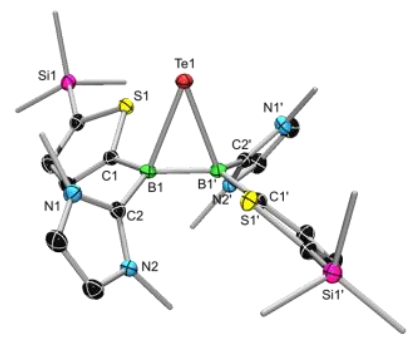

3

Figure 1. Synthesis and crystallographically determined structures of $\mathbf{2}$ and $\mathbf{3}$. The ellipsoids represent $50 \%$ probability, and have been omitted from the ligand periphery. For clarity, all hydrogen atoms are likewise omitted. Selected bond lengths $(\AA)$ and angles $\left({ }^{\circ}\right)$ : (2) B1-B2 1.707(3) , C2-B1 1.604(2), C1-B1 1.586(2), B1-Se1 2.115(2); (3) B1-B2 1.713(5), C1-B1 1.584(4), C2-B1 1.598(4), B1-Te1 2.360(3).

The B-B bonds in $2(1.707(3) \AA$ ) and $3(1.713(5) \AA$ ) are elongated with respect to the normal range of $B=B$ lengths in diborene compounds $(\sim 1.58-1.61 \AA),{ }^{[10,13]}$ just slightly short of the normal range for $\mathrm{B}-\mathrm{B}$ single bonds in base-stabilized neutral diboranes $\left(1.72\right.$ - 1.84). ${ }^{[13,14]}$ This mirrors the geometries of oxiranes, which tend to have C-C bond distances (1.438(4) $\AA$, ethylene oxide $)^{[15]}$ between those of alkanes $(1.532 \AA \text {, ethane })^{[16]}$ and alkenes (1.3142(3) $\AA$, ethylene).$^{[17]}$ The typical $\mathrm{C}-\mathrm{C}$ bonds in aziridines $(\sim 1.48 \AA)$ and thiirane $(\sim 1.49 \AA)$ are similarly situated between ethane and ethylene. ${ }^{[18]}$

Diborynes, molecules containing a boron-boron triple bond, ${ }^{[19]}$ are likewise known to be highly reducing. ${ }^{[11,19-20]}$ In fact, the reaction of the bis-NHC-stabilized diboryne $\mathrm{B}_{2} I \mathrm{Dip} \mathrm{p}_{2}(\mathbf{4}$, IDip = 1,3-[diisopropylphenyl]imidazol-2-ylidene) with elemental selenium was previously reported to result in a six-electron reduction inserting five selenium atoms between the two borons in the formation of a bicyclic compound consisting of two conjoined triselenadiborolane rings. ${ }^{[11]}$ An equivalent reaction using with elemental tellurium resulted in a complicated mixture of products from which no single major product could be isolated. In hopes of increasing the selectivity of the reaction by decreasing the oxidative power of the chalcogen, 4 was treated with 1,2-diphenylditelluride (Eq. 2). When the components were combined in benzene, a yellow precipitate fell from solution, which was isolated by filtration. The ${ }^{11} \mathrm{~B}$ NMR spectrum of this material showed one peak at $0 \mathrm{ppm}$, while the ${ }^{125} \mathrm{Te}$ NMR spectrum showed two very different peaks at 30 and $-328 \mathrm{ppm}$. The ${ }^{1} \mathrm{H}$ NMR spectrum of the product indicated two different phenyl environments. Single crystal X-ray analysis showed the formation of a salt complex (5) consisting of a cationic diboraphenyltellurenium fragment and a spatially separated anionic phenyltelluride. An equivalent reaction utilizing the more electron-poor di-[4-fluorophenyl]-ditellurium showed identical reactivity, allowing the isolation and characterization of 6 .

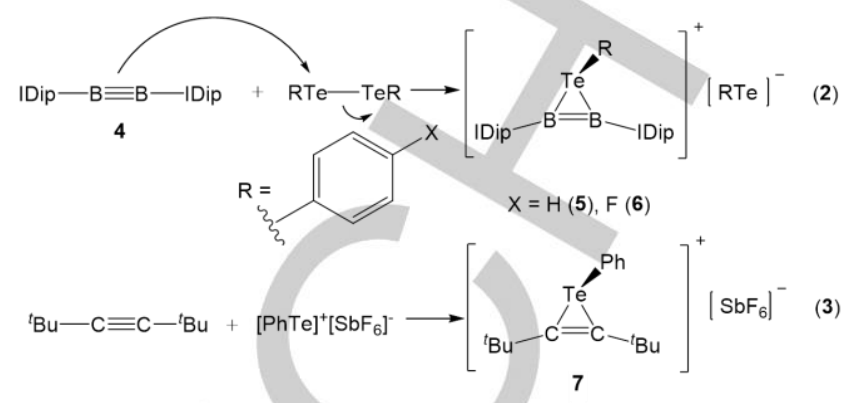

Similar organic three-membered tellurirenium ions (7, Eq. 3) have been previously demonstrated by Poleschner and Seppelt; ${ }^{[21]}$ however, the reaction pathway to these products is notably different. In the organic reaction, an $[\mathrm{ArTe}]^{+}$fragment is generated by oxidation of a ditelluride and subsequently reacted with an alkyne (Eq. 3). It seems that in order to facilitate the reaction with the more highly electronegative carbon atoms of the alkyne, the tellurium must be cationic. In the diboryne reaction, the presence of the anionic phenyltelluride in the product indicates a reaction pathway wherein the $\mathrm{B}=\mathrm{B}$ bond acts as a nucleophile, attacking one of the tellurium atoms of the ditelluride, forcing out a $[\mathrm{PhTe}]^{-}$leaving group. Such a process has been suggested as the pathway for the epoxidation of alkenes with peracids, ${ }^{[22]}$ though controversy surrounding this assertion still exists. ${ }^{[23]}$

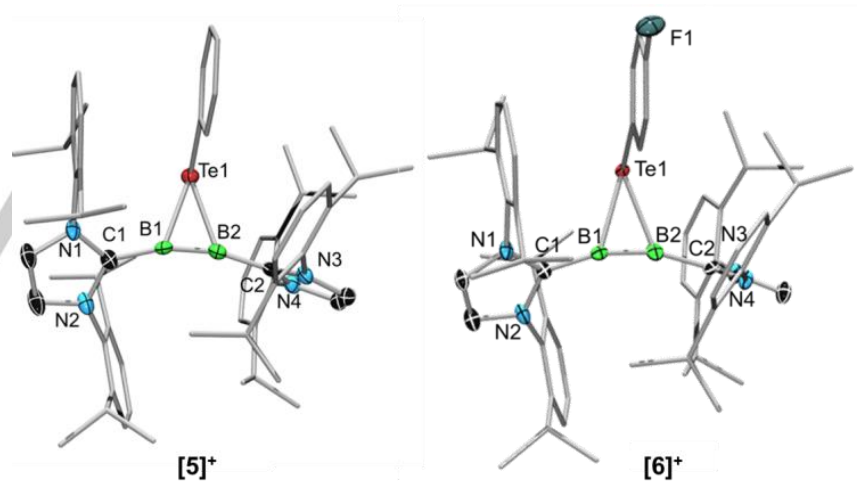

Figure 2. Crystallographically determined structures of [5] ${ }^{+}$and [6] ${ }^{+}$ (aryltelluride anions have been omitted). The ellipsoids represent 50\% probability, and have been omitted from the ligand periphery. For clarity, all hydrogen atoms are likewise omitted. Selected bond lengths $(\AA)$ and angles $\left.{ }^{\circ}\right)$ : (5) B1-B2 1.490(6) , C1-B1 1.551(5) , C2-B2 1.552(5), B1-Te1 2.260(4), B2-Te1 2.247(4), C1-B1-B2 165.0(4), C2-B2-B1 164.1(3), C1- B1- Te1 123.9(3), C2- B2-Te1 124.8(2); (6) B1-B2 1.494(10), C1-B1 1.545(9), C2-B2 1.559(10), B1-Te1 2.254(7), B2-Te1 2.243(8), C1-B1-B2 164.7(7), C2-B2B1 163.6(7), C1-B1-Te1 123.7(5), C2-B2-Te1 125.4(5).

The boron-boron bond lengths in $\mathbf{5}$ and $\mathbf{6}$ were found to be 1.490 (6) $\AA$ and $1.494(10) \AA$, respectively. These are moderately longer than the $B=B$ length in $1(1.449(3) \AA),{ }^{[19]}$ yet substantially shorter than those typically found in diborenes $(\sim 1.58-1.61$ $\AA) .{ }^{[10,13]}$ Similar structural features are found in the organic 
tellurirenium, which has a central $\mathrm{C}-\mathrm{C}$ bond measuring $1.288(14) \AA^{[21 a]}$ - longer than the central bond in di-tert-butyl acetylene $(1.202(2) \AA)^{[24]}$ but significantly shorter than the $\sim 1.34$ $\AA$ typical of the double bond in alkenes. ${ }^{[25]}$ The B-B-C angles in 5 and $6\left(\sim 163-165^{\circ}\right)$ are only slightly bent from linearity, though it is possible that the steric bulk of the two IDip groups prevents more acute bending. These angles are slightly more linear than the $\mathrm{C}-\mathrm{C}-\mathrm{C}_{\mathrm{tBu}}$ angles in $\mathrm{I}$, which measure 1.555(10) and 1.576(9) $\AA^{[21 a]}$ The Te atoms of $\mathbf{5}$ and $\mathbf{6}$ are highly pyramidalized, which is unsurprising since a planar tricoordinate Te atom would necessarily place two electrons into the $\pi$ system between the boron atoms, resulting in an antiaromatic electron count of four.

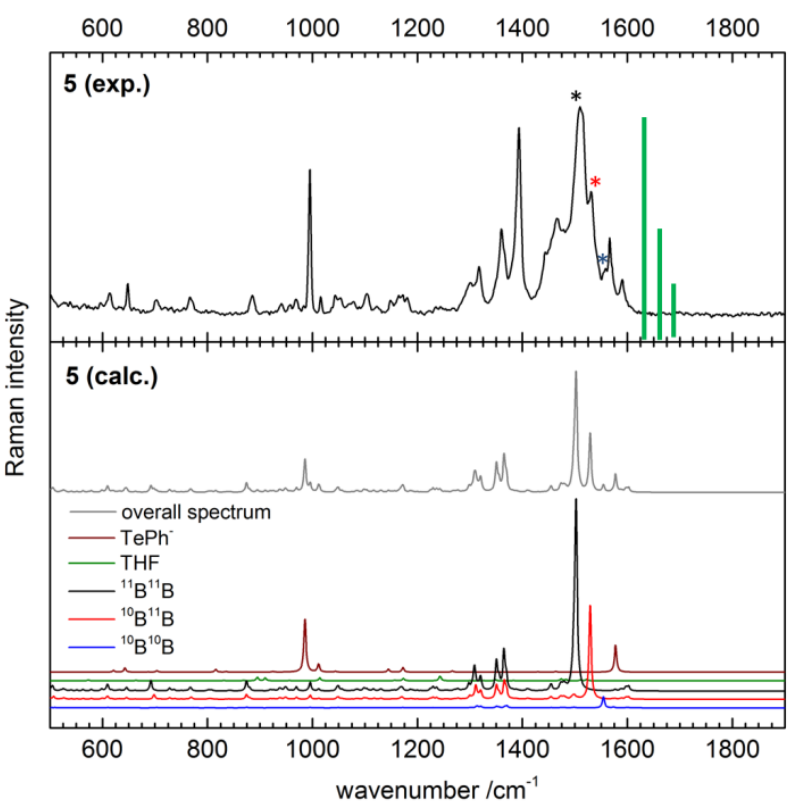

Figure 3. Comparison of the experimentally measured and DFT simulated Raman spectrum of $\mathbf{5}$. The multicolored spectra represent the calculated Raman spectra for the three constitutive isotopologues of $\mathbf{5}$ as well as THF bound in the crystal. The grey line represents the summation of all five listed spectra. The green vertical lines in the experimental spectrum (top) represent the positions of the Raman peaks previously reported for $\mathbf{4}$.

The relatively slight deviation from linearity induced by the complexation of $[\mathrm{PhTe}]^{+}$led us to seek additional information about the boron-boron bonds in $\mathbf{5}$ and $\mathbf{6}$. The Raman spectrum of 4 , previously used to study the strength of the $B=B$ triple bond, ${ }^{[26]}$ shows identifiable peaks at 1628,1657 and $1685 \mathrm{~cm}^{-1}$ corresponding to the symmetric stretch of the three possible isotopomeric combinations of ${ }^{11} \mathrm{~B}$ and ${ }^{10} \mathrm{~B}$. The spectra recorded with $\mathbf{5}$ and $\mathbf{6}$ showed a similar diagnostic isotopic pattern, shifted to lower wavenumbers, as a result of bond lengthening and a decrease in bond order. The spectrum of $\mathbf{5}$, in combination with the predicted spectra of its isotopomers, is presented in Figure 3 showing $B=B$ frequencies of 1511,1531 and 1555 (tentatively) $\mathrm{cm}^{-1}$ for the ${ }^{11} \mathrm{~B} /{ }^{11} \mathrm{~B},{ }^{11} \mathrm{~B} /{ }^{10} \mathrm{~B}$, and ${ }^{10} \mathrm{~B} /{ }^{10} \mathrm{~B}$ isotopomers, respectively. Compound 6 showed a very similar spectrum, which is provided in Figure S3. For comparison, the stretching frequencies attributed to the $\mathrm{B}=\mathrm{B}$ stretch in $\mathbf{4}$ are given in Figure
3 in green. Though direct comparison to organic tellurenium species such as 7 was not possible, as these compounds lack Raman data, the redshifting of the $B_{2}$ stretch $\left(\Delta v=\sim 120 \mathrm{~cm}^{-1}\right)$ upon going from $\mathbf{4}$ to $\mathbf{5}$ is significantly smaller than the redshift observed between $\mathrm{C} \equiv \mathrm{C}$ triple bonds and the central $\mathrm{C}_{2}$ stretch in similarly structured selenirenium ions $\left(\Delta v=\sim 380 \mathrm{~cm}^{-1}\right) .{ }^{[21 a]}$

In conclusion, the use of highly reducing boron-boron multiple bonds has enabled the formation of new, small heterocycles incorporating the heavy chalcogens, which are too electropositive to form similar compounds with carbon. The willingness of these $\pi$-bonds between boron atoms to donate electrons was explicitly shown in their capacity to act as nucleophiles in conjunction with ditellurides in the formation of diboratellurenium cations accompanied by anionic telluride anions. These reactions serve to highlight both the similarities and differences between boron-boron multiple bonds and their conventional unsaturated organic analogs. Both are capable of sequestering chalogen atoms into three membered rings, but the specific chalcogens employed, and the mechanism of their insertion, depends on the relative electronegativities of the chalcogen in question and boron or carbon. With this lesson learned, we continue to seek out reactions which fail with electron poor alkenes, in hopes that increasing the reductive power of the double bond may enable the chemistry to flourish.

\section{Acknowledgements}

H.B. wishes to acknowledge the generous financial support provided by an ERC Advanced Grant.

Keywords: Boron • Multiple Bonds • Heterocycles • Selenium • Tellurium

[1] For an abridged list of reviews on epoxidation of alkenes since 2000 see: a) Y. Zhu, Q. Wang, R. G. Cornwall, Y. Shi, Chem. Rev. 2014, 114, 8199-8256; b) Q.-H. Xia, H.-Q. Ge, C.-P. Ye, Z.-M. Liu, K.-X. Su, Chem. Rev. 2005, 105, 1603-166; c) Y. Shi, Acc. Chem. Res. 2004, 37, 488496; d) G. De Faveri, G. Ilyashenko, M, Watkinson, Chem. Soc. Rev. 2011, 40, 1722-1760; e) K. M. Weiß, S.B. Tsogoeva, Chem. Rec. 2011, 11, 18-39; f) J. W. Kück, R. M. Reich, F. E. Kühn, Chem. Rec. 2016, DOI: $10.1002 /$ tcr.201500233; g) M. J. Portera, J. Skidmore, Chem. Commun. 2000, 1215-1225; h) G. Grigoropoulou, J. H. Clark, J. A. Elings, Green Chem. 2003, 5, 1-7.

[2] For reviews on the aziridination of alkenes see: a) L. Degennaro, $P$. Trinchera, R. Luisi, Chem. Rev. 2014, 114, 7881-7929; b) J. B. Sweeny, Chem. Soc. Rev. 2002, 31, 247-258; A. Padwa in Comprehensive Heterocyclic Chemistry III (Eds. A. R. Katritzky, C. A. Ramsden, E. F.V. Scriven, R. J.K. Taylor), Elsevier, 2008, pp. 43-82; c) D. Tanner, Angew. Chem. Int. Ed. Engl. 1994, 33, 599-619; d) T. G. Driver, Org. Biomol. Chem. 2010, 8, 3831-3846.

[3] W. Adam, R. M. Bargon, W. A. Schenk, J. Am. Chem. Soc. 2003, 125 3871-3876; b) W. Adam, R. M. Bargon, Chem. Commun. 2001, 1910 1911; c) M. M. T. Khan, M. R. H. Siddiqui, Inorg. Chem. 1991, 30, 1157-1159.

[4] a) M. Sander, Chem. Rev. 1966, 66, 297-339; b) W. Chew, D. N Harpp, Sulfur Reports 1993, 15, 1-39; c) L. Goodman, E. J. Reist in The Chemistry of Organic Sulfur Compounds, Vol 2. (Eds.: N. Kharash, C. Y. Meyers), Pergamon Press Ltd., Oxford, 1966, pp. 93-114.

[5] a) E. M. Lown, H. S. Sandhu, H. E. Gunning, O. P. Strausz, J. Am. Chem. Soc. 1968, 90, 7164-7165; b) R. D. Adams, J. A. Queisser, J. H. 
Yamamoto, J. Am. Chem. Soc. 1996, 118, 10674-10675; c) W. Ando, N. Choi, N. Tokitoh in Comprehensive Heterocyclic Chemistry II (Eds.: A R. Katritzky, C. W. Rees, E. F. Scriven), Vol. 1A (Ed.: A. Padwa), Pergamon, Oxford, 1996.

[6] A. Ibdah, W. S. Jenks, J. H. Espenson, Inorg. Chem. 2006, 45, 5351-5357.

[7] D. Van Ende, A. Krief, Tetrahedron Lett. 1975, 31, 2709-2712; b) A Zhou, M. Segi T. Nakajima Tetrahedron Lett. 2003, 44, 1179-1182; c) K. Okuma, G. Koda, S. Okumura, A. Ohno, Chem. Lett. 1996, 8, 609 610 ; d) T. H. Ghan, J. R. Finkenbine, Tetrahedron Lett. 1974, 15 2091-2094.

[8] a) W. Ando, Y. Kumamoto, N. Tokitoh, J. Phys. Org. Chem. 1988, 1 317-322; b) W. Ando, Y. Kumamoto, N. Tokitoh, Tetrahedron Lett. 1987 28, 2867-2870; c) S. Dolai, P. Dutta, B. B. Muhoberac, C. D. Irving, R. Sardar, Chem. Mater. 2015, 27, 1057-1070.

[9] H. Braunschweig, R. D. Dewhurst, Organometallics 2014, 33, 6271-6277.

[10] a) P. Bissinger, H. Braunschweig, A. Damme, C, Hörl, I. Krummenacher, T. Kupfer, Angew. Chem. Int. Ed. 2015, 54, 359-362; b) P. Bissinger, H. Braunschweig, A. Damme, T. Kupfer, A. Vargas, Angew. Chem. Int. Ed. 2012, 124, 10069-10073; c) P. Bissinger, H. Braunschweig, A. Damme, T. Kupfer, I. Krummenacher, A. Vargas, Angew. Chem. Int. Ed. 2014, 53, 5689-5693.

[11] H. Braunschweig, T. Dellermann, W. C. Ewing, T. Kramer, C. Schneider, S. Ullrich, Angew. Chem. Int. Ed. 2015, 54,10271-10275.

[12] The calculated frontier molecular orbitals of compounds $\mathbf{2}, \mathbf{3}$, and 5 are given in Figures $\mathrm{S} 1$ and $\mathrm{S} 2$ of the Supplementary information

[13] a) Y. Wang, B. Quillian, P. Wei, C. S. Wannere, Y. Xie, R. B. King, H. F. Schaefer, P. v. R. Schleyer, G. H. Robinson, J. Am. Chem. Soc, 2007 129, 12412-12413; b) J. Böhnke, H. Braunschweig, T. Dellermann, W.
C. Ewing, T. Kramer, I. Krummenacher, A. Vargas, Angew. Chem. Int. Ed. 2015, 54,4469-4473.

[14] J. Böhnke, H. Braunschweig, W. C. Ewing, C. Hörl, T. Kramer, I. Krummenacher, J. Mies, A. Vargas, Angew. Chem. Int. Ed. 2014, 53 9082-9085.

[15] P. Luger, C. Zaki. J. Buschmann, R. Rudert, Angew. Chem. 1986, 98, 254-255.

[16] G. J. H. Van Nes, A. Vos, Acta Cryst. 1978, B34, 1947-1956.

[17] G. J. H. Van Nes, A. Vos, Acta Cryst. 1978, B34, 2593-2601.

[18] F. H. Allen, Tetrahedron 1982, 38, 2843-2853.

[19] H. Braunschweig, R. D. Dewhurst, K. Hammond, J. Mies, K. Radacki, A Vargas, Science 2012, 336, 1420-1422.

[20] H. Braunschweig, T. Dellermann, R. D. Dewhurst, W. C. Ewing, K Hammond, J. O. C. Jimenez-Halla, T. Kramer, I. Krummenacher, J. Mies, A. K. Phukan, A. Vargas, Nature Chem. 2013, 5, 1025-1028.

[21] a) H. Poleschner, K. Seppelt, Angew. Chem. Int. Ed. 2008, 47, 64616464; b) H. Poleschner, K. Seppelt, Angew. Chem. Int. Ed. 2013, 52, 12838-12842

[22] a) Bartlett, P. D. Rec. Chem. Progr. 1950, 11, 47-50; b) H. Shi, Z. Zhang, Y. Wang, J. Mol. Catal. A: Chem. 2005, 238, 13-25

[23] a) A. Rybina, C. Lang, M. Wirtz, K. Grußmayer, A. Kurz, F. Maier, A. Schmitt, O. Trapp, G. Jung, D.-P. Herten, Angew. Chem. Int. Ed. 2013 52, 6322-6325; b) D. I. Metelitsa, Russ. Chem. Rev. 1972, 41, 807-821.

[24] R. Boese, D. Bläser, R. Latz, A. Bäumen, Acta Cryst. 1999, C55, IUC9900016.

[25] L. E. Sutton (ed.) in Table of interatomic distances and configuration in molecules and ions, Supplement 1956-1959, Special publication No. 18, Chemical Society, London, UK, 1965.

[26] J. Böhnke, H. Braunschweig, P. Constantinidis, T. Dellermann, W. C Ewing, I. Fischer, K. Hammond, F. Hupp, J. Mies, H.-C. Schmitt, A. Vargas, J. Am. Chem. Soc. 2015, 137, 1766-1769. 
Entry for the Table of Contents (Please choose one layout)

Layout 1:

\section{COMMUNICATION}

Heavy heterocycles: The reaction of diborenes with $\mathrm{Se}$ and Te resulted in the formation of diboraseleniranes and diboratelluriranes, while the reaction of diborynes with diarylditellurides yields diboratellurenium cations with arytelluride anions. Such reactions are unique to boron-boron multiple bonds due to their reducing nature and the relatively low electronegativity of boron.

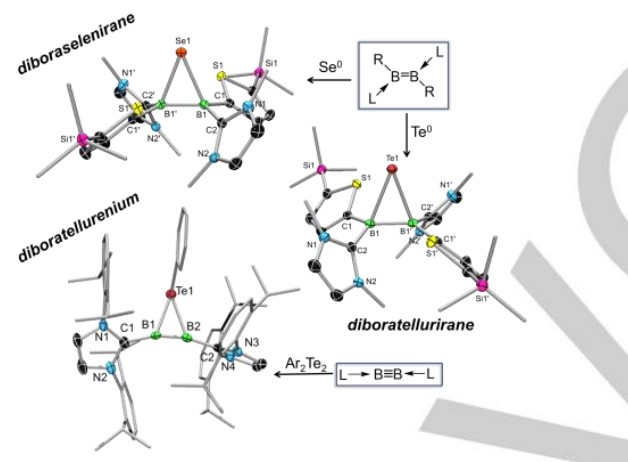

Holger Braunschweig, ${ }^{*}$ Philipp Constantinidis, Theresa Dellermann, William C. Ewing, Ingo Fischer, Merlin Hess, Fergus R. Knight, Phillip Nejman, Anna Rempel, Christoph Schneider, Stefan Ullrich, Alfredo Vargas, J. Derek Woollins

Page No. - Page No.

Highly Strained Heterocycles Constructed from Boron-Boron Multiple Bonds and Heavy Chalcogens 